International Journal of Applied Research 2021; 7(2): 13-17

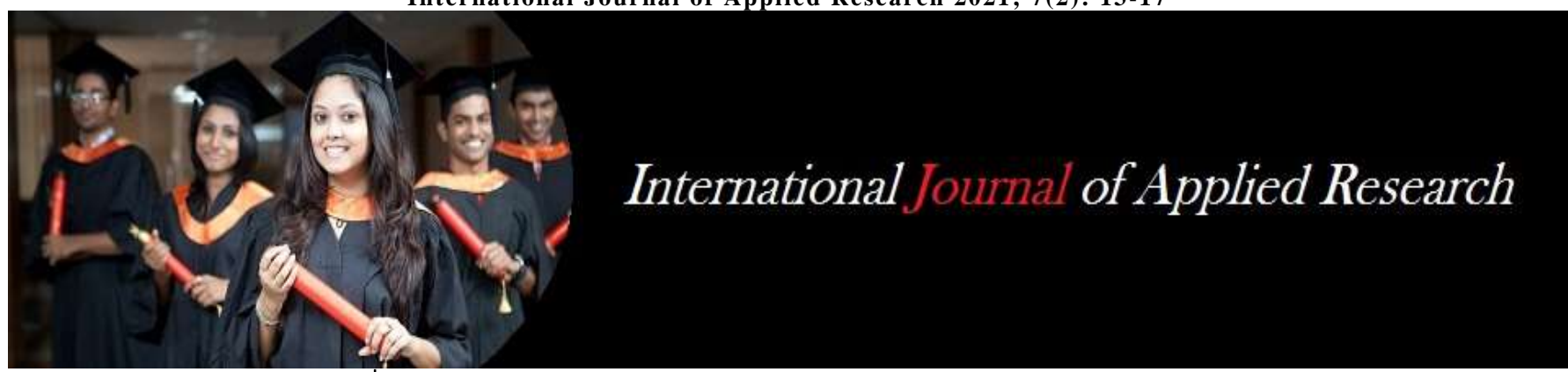

ISSN Print: 2394-7500

ISSN Online: 2394-5869

Impact Factor: 8.4

IJAR 2021; 7(2): 13-17

www.allresearchjournal.com

Received: 06-12-2020

Accepted: 08-01-2021

डा० सरिता गोस्वामी

ऐसोसिएट प्रोफेसर, विभागाध्यक्ष,

शिक्षा विभाग, आई०आई०एम०टी० यूनिवर्सिटी, मेरठ, उत्तर प्रदेश, भारत
Corresponding Author: डा० सरिता गोस्वामी ऐसोसिएट प्रोफेसर, विभागाध्यक्ष, शिक्षा विभाग, आई०आई०एम०टी० यूनिवर्सिटी, मेरठ, उत्तर प्रदेश, भारत

\section{मेरठ जिले के माध्यमिक स्तर के विद्यार्थियों की विभिन्न व्यावसायिक रुचियों का तुलनात्मक अध्ययन}

\section{डा० सरिता गोस्वामी}

DOI: https://doi.org/10.22271/allresearch.2021.v7.i2a.8226

सारांश

प्रस्तुत शोध अध्ययन में मेरठ जिले के माध्यमिक स्तर के विद्यार्थियों की विभिन्न व्यावसायिक रुचियों का अध्ययन किया गया है। इस अध्ययन हेतु मेरठ जिले के विभिन्न स्कूलों में अध्ययनरत 100 विद्यार्थियों (50 छात्र एवं 50 छात्राओं) का न्यादर्श चयन, स्तरीकरण विधि द्वारा किया गया है। प्रस्तुत अध्ययन के आंकड़ों के संकलन के लिये डा० एस० पी०० कुलश्रेष्ठ द्वारा निर्मित "व्यावसायिक रुचि प्रपत्र मापनी" का चयन किया गया है। प्राप्त प्रदत्तों के विश्लेषण के लिये मध्यमान, मानक विचलन व टी० परीक्षण का प्रयोग किया गया और निष्कर्ष में पाया गया कि लिंगीय आधार पर माध्यमिक स्तर के छात्र एवं छात्राओं की व्यावसायिक रुचियों के अधिकांश क्षेत्रों में कोई सार्थक अन्तर नहीं है; केवल मात्र एक व्यावसायि रुचि क्षेत्र रचनात्मक (Co) में सार्थक अन्तर पाया गया है। सांकेतिक शब्द : व्यावसायिक रुचि, माध्यमिक विद्यालय।

मुख्य शब्द : व्यावसायिक रुचियों, तुलनात्मक अध्ययन, मध्यमान, मानक

\section{प्रस्तावनाः}

मानव प्रकृति का सर्वाधिक बुद्धिमान प्राणी तथा ईश्वर की अन्य कृतियों में सर्वश्रेष्ठ कहा जाता है। इस तथ्य के मूल म 'शिक्षा' ही वह आधारभूत प्रक्रिया है, जिसमें मानव का पूर्ण विकास होता है।

शिक्षा का उद्भव 'सृष्टि' में मानव के सृजन के साथ ही प्रारम्भ हो गया था। शिक्षा के विभिन्न उद्देश्यों में से एक प्रमुख उद्देश्य जीविकोपार्जन के लिये मार्गदर्शन करना भी है। इस उद्देश्य की पूर्ति हेतु व्यावसायिक शिक्षा अत्यन्त आवश्यक है। व्यावसायिक शिक्षा की प्राप्ति के लिये व्यावसायिक प्रशिक्षण की आवश्यकता होती है, जिसके अन्तर्गत छात्रों में श्रम के प्रति आदर व रुचि उत्पन्न करना व हस्तकला के कार्यों को महत्व देना परमावश्यक है।

महात्मा गाँधी जी के अनुसार, "शिक्षा को बेरोजगारी के विरुद्ध एक बीमा होना चाहिये।" अर्थात् शिक्षा में व्यावसायिक दृष्टिकोण का होना अत्यन्त आवश्यक है।

समस्या की उत्पत्ति :

भारत में व्यावसायिक शिक्षा की परम्परा अत्यन्त प्राचीन है। प्रारम्भ में अधिकांशतया बालक अपने माता-पिता से घर पर ही अनौपचारिक रूप में इस शिक्षा को ग्रहण करते थे। संगठित रूप में व्यावसायिक शिक्षा ब्रिटिश युग की देन है। सर्वप्रथम व्यावसायिक शिक्षा अंग्रेजी सरकार की आवश्यकताओं पर निर्भर करती थी। भारत में तत्कालीन कुछ कॉलेजों व महाविद्यालयों में व्यावसायिक व प्राविधिक शिक्षा प्रदान करने हेतु विशेष व्यावसायिक विद्यालय खोले गये। स्वतन्त्रता प्राप्ति के पश्चात् सभी विचारकों, शिक्षाविदों, नेतागणों व विभिन्न शिक्षा आयोगों द्वारा भी शिक्षा के व्यावसायीकरण की आवश्यकता पर जोर दिया।

शिक्षा के व्यावसायीकरण की आवश्यकता का आंकलन निम्न बिन्दुओं से किया जा सकता है :

1. बेरोजगारी की समाधान।

2. छात्रों में विभिन्न क्षमताओं व योग्यताओं का विकास।

3. देश का आर्थिक विकास।

4. सामाजक समायोजन का विकास।

5. सामाजिक दक्षता की प्राप्ति।

6. नैतिक मूल्यों का विकास।

प्रस्तुत अध्ययन का मुख्य उद्देश्य माध्यमिक विद्यालय के छात्रों की व्यावसायिक रुचियों को जानना है। 
यह एक निर्विवाद सत्य है कि प्रकृति निर्मित कोई भी दो वस्तुएँ एक समान नहीं होती हैं; उसमें किसी न किसी रूप में अन्तर पाया जाता है। इसी प्रकार छात्र-छात्राओं की रुचियों में अन्तर पाया जाता है। मनोवैज्ञानिक दृष्टि से बालक व बालिकाओं की शिक्षा में व्यक्तिगत विभिन्नता का महत्वपूर्ण स्थान है अतः व्यक्तिगत विभिन्नता के आधार पर शिक्षा की आवश्यकता का शैक्षिक व व्यावसायिक निर्देशन की दृष्टि से भी अत्यन्त महत्वपूर्ण स्थान है।

माध्यमिक स्तर पर 13 से 15 वर्ष की आयु के छात्र-छात्राओं की रुचियाँ स्थाई नहीं होती हैं परन्तु 18 से 19 वर्ष की आयु के किशोरों की अभिरुचियाँ अधिक स्थाई हो जाती हैं। छात्रों की रुचियों का उनकी शैक्षिक सफलता पर अधिक प्रभाव पड़ता है। व्यवसाय व रुचि दोनों एक सिक्के के दो पहलुओं के समान हैं अर्थात् एक-दूसरे से घनिष्ट रूप में सम्बधित है।

\section{अध्ययन की सार्थकता :}

वर्तमान औद्योगीकरण के युग में नवीन व्यवसायों की संख्या में निरन्तर वृद्धि हो रही है। ऐसे समय में विभिन्न प्रकार के व्यवसायों में से किन व्यवसायों का चयन करें, यह एक प्रमुख समस्या है। इसके लिये पर्याप्त व्यावसायिक निर्देशन की आवश्यकता होती है। व्यावसायिक चयन एक विकास की प्रक्रिया है जो माध्यमिक विद्यालयी शिक्षा के समय में छात्रों की आकांक्षाओं के अन्वेषण से प्रारम्भ होकर व्यावसायिक परिपक्वता, रुचियों, मूल्यों व क्षमताओं की एक विस्तृत श्रृंखला होती है। माध्यमिक स्तर पर यदि छात्रों को उचित निर्देशन नहीं दिया जाता है तो भविष्य में वे समाज में समायोजन करने में असफल रहते हैं। इस स्तर पर छात्रों की चिन्तन क्षमता विकसित होने लगती है। वह यह चिन्तन करना प्रारम्भ कर देता है कि उसे किस क्षेत्र में व्यवसाय का चयन करना चाहिये। ऐसे में छात्रों की व्यक्तिगत विशेषताओं व व्यावसायिक विकल्पों का संज्ञान करने के लिये कई प्रकार की मार्गदर्शन गतिविधियों व अवसरों की आवश्यकता होती है। शोधकर्ती इस बात से सहमत हैं कि अनुभव के परिणामस्वरूप रुचियों का विकास होता है। माध्यमिक विद्यालयी स्तर पर छात्रों को अनुभवों को गृहण करने के लिये प्रेरित करना चाहिये। क्योंकि छात्र शैक्षिक व व्यावसायिक विकल्पों की जानकारी प्राप्त करके ही सही व्यावसायिक निर्णय लेने में समर्थ हो पाते हैं। इसलिये शिक्षा व व्यवसाय छात्रों की रुचि से सम्बन्धित होता है। प्रस्तुत अध्ययन में यही उद्देश्य निहित है कि शिक्षा को व्यावसायिक हितों से सम्बन्धित करने से छात्र अपने व्यक्तित्व व रुचियों के क्षेत्रों को विस्तृत करने की योग्यता प्राप्त कर सकते हैं।

छात्र अपने कौशल व योग्यता का व्यावसायिक रुचियों के साथ आंकलन कर सकते हैं, अपनी भविष्य की योजना के लिये आत्मज्ञान विकसित करके अपने निर्णयों पर नियन्त्रण करना सीख सकते हैं।

\section{समस्या का कथन}

"मेरठ जिले के माध्यमिक स्तर के छात्र एवं छात्राओं की विभिन्न व्यावसायिक रुचियों का तुलनात्मक अध्ययन"

\section{अध्ययन के उद्देश्य}

1. माध्यमिक स्तर के छात्र एवं छात्राओं की साहित्यिक क्षेत्र की व्यावसायिक रुचियों की तुलना करना।

2. माध्यमिक स्तर के छात्र एवं छात्राओं की वैज्ञानिक क्षेत्र में व्यावसायिक रुचियों की तुलना करना।

3. माध्यमिक स्तर के छात्र एवं छात्राओं की शासन सम्बन्धी क्षेत्र की व्यावसायिक रुचियों की तुलना करना।

4. माध्यमिक स्तर के छात्र एवं छात्राओं की वाणिज्य क्षेत्र की व्यावसायिक रुचियों की तुलना करना।
5. माध्यमिक स्तर के छात्र एवं छात्राओं की रचनात्मक क्षेत्र की व्यावसायिक रुचियों की तुलना करना।

6. माध्यमिक स्तर के छात्र एवं छात्राओं की कलात्मक क्षेत्र की व्यावसायिक रुचियों की तुलना करना।

7. माध्यमिक स्तर के छात्र एवं छात्राओं की कृषि क्षेत्र की व्यावसायिक रुचियों की तुलना करना।

8. माध्यमिक स्तर के छात्र एवं छात्राओं की प्रवर्तक क्षेत्र की व्यावसायिक रुचियों की तुलना करना।

9. माध्यमिक स्तर के छात्र एवं छात्राओं की सामाजिक क्षेत्र की व्यावसायिक रुचियों की तुलना करना।

10. माध्यमिक स्तर के छात्र एवं छात्राओं की गृह सम्बन्धी क्षेत्र की व्यावसायिक रुचियों की तुलना करना।

\section{परिकल्पनाएँ}

1. माध्यमिक स्तर के छात्र एवं छात्राओं की साहित्यक ;स्द्ध क्षेत्र की व्यावसायिक रुचियों में कोई सार्थक अन्तर नहीं है।

2. माध्यमिक स्तर के छात्र एवं छात्राओं की वैज्ञानिक ";बद्ध क्षेत्र की व्यावसायिक रुचियों में कोई सार्थक अन्तर नहीं है।

3. माध्यमिक स्तर के छात्र एवं छात्राओं की शासन ;म्द्ध क्षेत्र की व्यावसायिक रुचियों में कोई सार्थक अन्तर नहीं है।

4. माध्यमिक स्तर के छात्र एवं छात्राओं की वाणिज्य ;ब्द्ध क्षेत्र की व्यावसायिक रुचियों में कोई सार्थक अन्तर नहीं है।

5. माध्यमिक स्तर के छात्र एवं छात्राओं की रचनात्मक ;ब्वद्ध क्षेत्र की व्यावसायिक रुचियों में कोई सार्थक अन्तर नहीं है।

6. माध्यमिक स्तर के छात्र एवं छात्राओं की कलात्मक ; द्ध क्षेत्र की व्यावसायिक रुचियों में कोई सार्थक अन्तर नहीं है।

7. माध्यमिक स्तर के छात्र एवं छात्राओं की कृषि ; हहद्ध क्षेत्र की व्यावसायिक रुचियों में कोई सार्थक अन्तर नहीं है।

8. माध्यमिक स्तर के छात्र एवं छात्राओं की प्रवर्तक ;च्द्ध क्षेत्र की व्यावसायिक रुचियों में कोई सार्थक अन्तर नहीं है।

9. माध्यमिक स्तर के छात्र एवं छात्राओं की सामाजिक ";द्ध क्षेत्र की व्यावसायिक रुचियों में कोई सार्थक अन्तर नहीं है।

10. माध्यमिक स्तर के छात्र एवं छात्राओं की गृह ; भ्द्ध क्षेत्र की व्यावसायिक रुचियों में कोई सार्थक अन्तर नहीं है।

\section{तकनीकी शब्दों का परिभाषीकरण}

माध्यमिक विद्यालय-माध्यमिक शिक्षा अथवा विद्यालयों से तात्पर्य उन विद्यालयों से है, जिनमें कक्षा 9 से 10 तक के छात्र एवं छात्राएँ ध्ययन करते हैं, जहाँ गणित, विज्ञान, कला, वाणिज्य, मानविकी तथा कृषि आदि विभिन्न विषयों की शिक्षा दी जाती है।

व्यावसायिक रुचि-इसके अन्तर्गत व्यक्ति वस्तुओं या क्रियाओं का चयन करके उसे पसन्द, नापसन्द के रूप में कोटिबद्ध करता है। अतः व्यावसायिक रुचि किसी वस्तु से सम्बन्ध जोड़ने वाली मानसिक संरचना है, जब बालकों एवं बालिकाओं का किसी कार्य के प्रति ध्यान केन्द्रित होता है, तो वह उसकी व्यावसायिक रुचि कहलाती है। जो कार्य व्यक्ति की मानसिक शक्तियों, क्षमताओं, रुचियों, शैक्षिक योग्यताओं, शारीरिक क्षमताओं और व्यक्ति की विशेषताओं के अनुकूल हो तो उससे सम्बन्धित कार्य करने में उसे सुविधा रहती है तथा उन्हीं कार्यों को करने में वह अधिक रुचि प्रकट करता है। व्यवसायों की सफलता व्यक्ति की मानसिक क्षमता व रुचि पर निर्भर करती है।

\section{शोध प्रविधि}

शोधकर्ती ने शोध के उद्देश्यों को दृष्टिगत रखते हुए सर्वेक्षण विधि का प्रयोग किया है।

\section{जनसंख्या}

शोधकर्ती ने मेरठ पश्चिमी उत्तर प्रदेश के कक्षा 9 व 10 के माध्यमिक विद्यालयों के विद्यार्थियों को सम्मिलित किया हैं 
शोधकर्ती ने मेरठ के माध्यमिक विद्यालयों का चयन सरल अनियत विधि द्वारा किया तथा स्तरीकृत न्यादर्श विधि द्वारा दो विद्यालयों से 100 छात्रों (50 छात्र एवं 50 छात्राओं) का चयन किया है।

\section{चरों का मापन यंत्र}

व्यावसायिक रुचि प्रपत्र यंत्र (निर्माण डॉ० एस० पी० कुलश्रेष्ठ) इस व्यावसायिक रुचि प्रपत्र में रुचियों से सम्बन्धित 200 प्रश्न हैं, जो 10 प्रकार की व्यावसायिक रुचि क्षेत्रों से सम्बन्धित है। इस परीक्षण में 10 व्यावसायिक क्षेत्र-साहित्यिक (L), वैज्ञानिक (SC), शासन सम्बन्धी (E), व्यावसायिक (C), रचनात्मक (Co), कलात्मक (A), कृषि सम्बन्धी $(\mathrm{Ag})$, प्रवर्तक $(\mathrm{P})$, सामाजिक (S), गृह सम्बन्धी $(\mathrm{H})$ सम्मिलित हैं। प्रत्येक क्षेत्र में 20 कार्य या प्रश्न हैं, जिनमें 10 उद्धर्वाधर और 10 क्षैतिज दिशा में हैं। व्यावसायिक रुचि प्रपत्र में किसी एक व्यावसायिक क्षेत्र में अधिकतम प्राप्तांक 20 तथा न्यूनतम प्राप्तांक शून्य है। प्रत्येक क्षेत्र में दिये गये कार्यों के सम्मुख () पसन्द वाले को (3) चिन्ह को एक (1) अंक तथा नापसन्द वाले को (7) जीरो (0) अंक दिया
गया है। एक रुचि क्षेत्र के सभी (3) निशानों का जोड़ लिया जाता है; जैसे $\mathrm{L}_{1}$ महिला के क्षेत्र के उद्धर्वाकार खाने (3) के निशानों तथा $\mathrm{L}_{2}$ के क्षैतिज खाने (3) के निशानों को आपस में जोड़ लिया जाता है।

इस परीक्षण की विश्वसनीयता 15 दिनों के अन्तराल में विश्वसनीयता गुणांक 0.69 प्राप्त की गई। इस परीक्षण में केवल उच्च वैधता वाली वस्तुओं को थर्स्टन रुचि प्रपत्र, स्ट्रांगवोकेशनल इन्टैस्ट, ब्लैंक एवं कूडर प्रिफैंस रिकॉर्ड फार्म $\mathrm{C}$ से ली गई है।

\section{सांख्यिकी विधि}

सांख्यिकी विधि के अन्तर्गत मध्यमान (M) प्रमाप/मानव विचलन (S.D.) और टी-परीक्षण (t-test) का प्रयोग किया गया है।

\section{प्रदत्त विश्लेषण एवं व्याख्या :}

प्रस्तुत अध्याय में परिकल्पनाओं के परीक्षण से सम्बन्धित आँकड़ों का क्रमबद्ध रूप में सारणीकृत करके उनका विश्लेषण किया जाता है।

तालिका संख्या-1: माध्यमिक स्तर के छात्र एवं छात्राओं की साहित्यिक (L) क्षेत्र की व्यावसायिक रुचियों की तुलना करना

\begin{tabular}{|c|c|c|c|c|c|c|}
\hline \multirow{2}{*}{ व्यावसायिक क्षेत्र } & छात्राएँ (50) & & छात्र (50) & & \multirow{2}{*}{ ज मूल्य } & \multirow{2}{*}{ सार्थकता स्तर } \\
\cline { 2 - 6 } & $\mathbf{M}$ & S.D. & M & S.D. & & \\
\hline साहित्यक (L) & 8.58 & 13.03 & 8.24 & 10.09 & 0.146 & सार्थक नहीं \\
\hline
\end{tabular}

सार्थकता-सारणी संख्या 1 में माध्यमिक स्तर के छात्र एवं छात्राओं की साहित्यिक क्षेत्र की व्यावसायिक रुचियों की तुलना क्रान्तिक अनुपात (टी-मूल्य) के रूप में की गई है। प्राप्त टी-मान 0.146 है, जो सार्थकता के 0.05 पर सार्थक नहीं है। अतः कहा
जा सकता है कि मध्यमिक स्तर के छात्र एवं छात्राओं की साहित्यिक क्षेत्र की व्यावसायिक रुचियों में कोई सार्थक अन्तर नहीं है। अतः शून्य परिकल्पना को स्वीकार किया जाता है।

तालिका संख्या-2: माध्यमिक स्तर के छात्र एवं छात्राओं की वैज्ञानिक $(\mathrm{Sc})$ क्षेत्र की व्यावसायिक रुचियों की तुलना करना

\begin{tabular}{|c|c|c|c|c|c|c|}
\hline \multirow{2}{*}{ व्यावसायिक क्षेत्र } & छात्राएँ (50) & & छात्र (50) & & \multirow{2}{*}{ ज मूल्य } & \multirow{2}{*}{ सार्थकता स्तर } \\
\cline { 2 - 5 } & $\mathbf{M}$ & S.D. & $\mathbf{M}$ & S.D. & & \\
\hline वैज्ञानिक (Sc) & 9.76 & 2.88 & 8.8 & 2.96 & 1.64 & सार्थक नहीं \\
\hline
\end{tabular}

सार्थकता-सारणी संख्या 2 में माध्यमिक स्तर के छात्र एवं छात्राओं की वैज्ञानिक क्षेत्र की व्यावसायिक रुचियों की तुलना क्रान्तिक अनुपात (टी-मूल्य) के रूप में की गई है। प्राप्त टी-मान 1.64 है, जो सार्थकता के 0.05 पर सार्थक नहीं है। अतः कहा जा
सकता है कि माध्यमिक स्तर के छात्र एवं छात्राओं की वैज्ञानिक क्षेत्र की व्यवसायिक रुचियों में कोई सार्थक अन्तर नहीं है। अतः शून्य परिकल्पना को स्वीकार किया जाता है।

तालिका संख्या-3: माध्यमिक स्तर के छात्र एवं छात्राओं की शासन सम्बन्धी (E) क्षेत्र की व्यावसायिक रुचियों की तुलना करना

\begin{tabular}{|c|c|c|c|c|c|c|}
\hline \multirow{2}{*}{ व्यावसायिक क्षेत्र } & छात्राएँ (50) & & छात्र (50) & & \multirow{2}{*}{ ज मूल्य } & \multirow{2}{*}{ सार्थकता स्तर } \\
\cline { 2 - 6 } & $\mathbf{M}$ & S.D. & M & S.D. & & \\
\hline शासन सम्बन्धी (E) & 10.24 & 13.45 & 9.02 & 8.37 & 0.544 & सार्थक नहीं \\
\hline
\end{tabular}

सार्थकता-सारणी संख्या 3 में माध्यमिक स्तर के छात्र एवं छात्राओं की व्यावसायिक रुचियों के अन्तर्गत शासन सम्बन्धी क्षेत्र की तुलना क्रान्तिक अनुपात (टी-मूल्य) के रूप में की गई है। प्राप्त टी-मान 0.544 है, जो सार्थकता के 0.05 पर सार्थक नहीं
है। अतः कहा जा सकता है कि माध्यमिक स्तर के छात्र एवं छात्राओं की शासन सम्बन्धी क्षेत्र की व्यवसायिक रुचियों में कोई सार्थक अन्तर नहीं है। अतः शून्य परिकल्पना को स्वीकार किया जाता है।

तालिका संख्या-4: माध्यमिक स्तर के छात्र एवं छात्राओं की वाणिज्य (C) क्षेत्र की व्यावसायिक रुचियों की तुलना करना

\begin{tabular}{|c|c|c|c|c|c|c|}
\hline \multirow{2}{*}{ व्यावसायिक क्षेत्र } & छात्राएँ (50) & & छात्र (50) & & \multirow{2}{*}{ ज मूल्य } & \multirow{2}{*}{ सार्थकता स्तर } \\
\cline { 2 - 5 } & $\mathbf{M}$ & S.D. & $\mathbf{M}$ & S.D. & & \\
\hline वाणिज्य (C) & 8.24 & 13.79 & 8.6 & 6.89 & 0.055 & सार्थक नहीं \\
\hline
\end{tabular}

सार्थकता-सारणी संख्या 4 में माध्यमिक स्तर के छात्र एवं छात्राओं की वाणिज्य क्षेत्र की व्यावसायिक रुचियों की तुलना क्रान्तिक अनुपात (टी-मूल्य) के रूप में की गई है। प्राप्त टी-मान 055 है, जो सार्थकता के 0.055 पर सार्थक नहीं है। अतः कहा
जा सकता है कि माध्यमिक स्तर के छात्र एवं छात्राओं की वाणिज्य क्षेत्र की व्यवसायिक रुचियों में सार्थक अन्तर नहीं है। अतः शून्य परिकल्पना को अस्वीकार किया जाता है। 
तालिका संख्या-5: माध्यमिक स्तर के छात्र एवं छात्राओं की रचनात्मक (Co) क्षेत्र की व्यावसायिक रुचियों की तुलना करना

\begin{tabular}{|c|c|c|c|c|c|c|}
\hline \multirow{2}{*}{ व्यावसायिक क्षेत्र } & छात्राएँ (50) & & छात्र (50) & & \multirow{2}{*}{ ज मूल्य } & \multirow{2}{*}{ सार्थकता स्तर } \\
\cline { 2 - 7 } & $\mathbf{M}$ & S.D. & M & S.D. & & \\
\hline रचनात्मक $(\mathrm{Co})$ & 6.82 & 3.699 & 8.74 & 2.804 & 2.926 & सार्थक है \\
\hline
\end{tabular}

सार्थकता-सारणी संख्या 5 में माध्यमिक स्तर के छात्र एवं छात्राओं की रचनात्मक क्षेत्र की व्यावसायिक रुचियों की तुलना क्रान्तिक अनुपात (टी-मूल्य) के रूप में की गई है। प्राप्त टी-मान 2.926 है, जो सार्थकता के 0.05 पर सार्थक है। अतः कहा जा
सकता है कि माध्यमिक स्तर के छात्र एवं छात्राओं की रचनात्मक क्षेत्र की व्यवसायिक रुचियों में सार्थक अन्तर है। अतः शून्य परिकल्पना को अस्वीकार किया जाता है।

तालिका संख्या-6: माध्यमिक स्तर के छात्र एवं छात्राओं की कलात्मक (A) क्षेत्र की व्यावसायिक रुचियों की तुलना करना

\begin{tabular}{|c|c|c|c|c|c|c|}
\hline \multirow{2}{*}{ व्यावसायिक क्षेत्र } & छात्राएँ (50) & & छात्र (50) & & \multirow{2}{*}{ ज मूल्य } & \multirow{2}{*}{ सार्थकता स्तर } \\
\cline { 2 - 5 } & $\mathbf{M}$ & S.D. & $\mathbf{M}$ & S.D. & & \\
\hline कलात्मक (A) & 9.84 & 3.413 & 9.2 & 2.676 & 1.016 & सार्थक नहीं \\
\hline
\end{tabular}

सार्थकता-सारणी संख्या 6 में माध्यमिक स्तर के छात्र एवं छात्राओं की कलात्मक क्षेत्र की व्यावसायिक रुचियों की तुलना क्रान्तिक अनुपात (टी-मूल्य) के रूप में की गई है। प्राप्त टी-मान 1.016 है, जो सार्थकता के 0.05 पर सार्थक नहीं है। अतः कहा
जा सकता है कि माध्यमिक स्तर के छात्र एवं छात्राओं की कलात्मक क्षेत्र की व्यवसायिक रुचियों में कोई सार्थक अन्तर नहीं है। अतः शून्य परिकल्पना को स्वीकार किया जाता है।

तालिका संख्या-7: माध्यमिक स्तर के छात्र एवं छात्राओं की कृषि सम्बन्धी $(\mathrm{Ag})$ क्षेत्र की व्यावसायिक रुचियों की तुलना करना

\begin{tabular}{|c|c|c|c|c|c|c|}
\hline \multirow{2}{*}{ व्यावसायिक क्षेत्र } & छात्राएँ (50) & & छात्र (50) & & \multirow{2}{*}{ ज मूल्य } & \multirow{2}{*}{ सार्थकता स्तर } \\
\cline { 2 - 5 } & $\mathbf{M}$ & S.D. & M & S.D. & & \\
\hline कृषि सम्बन्धी $(\mathrm{Ag})$ & 7.78 & 3.699 & 8.96 & 3.042 & 1.74 & सार्थक नहीं \\
\hline
\end{tabular}

सार्थकता-सारणी संख्या 7 में माध्यमिक स्तर के छात्र एवं छात्राओं की कृषि सम्बन्धी क्षेत्र की व्यावसायिक रुचियों की तुलना क्रान्तिक अनुपात (टी-मूल्य) के रूप में की गई है। प्राप्त टी-मान 1.74 है, जो सार्थकता के 0.05 पर सार्थक नहीं है। अतः
कहा जा सकता है कि माध्यमिक स्तर के छात्र एवं छात्राओं की कृषि सम्बन्धी क्षेत्र की व्यवसायिक रुचियों में कोई सार्थक अन्तर नहीं है। अतः शून्य परिकल्पना को स्वीकार किया जाता है।

तालिका संख्या-8: माध्यमिक स्तर के छात्र एवं छात्राओं की प्रवर्तक $(\mathrm{P})$ क्षेत्र की व्यावसायिक रुचियों की तुलना करना

\begin{tabular}{|c|c|c|c|c|c|c|}
\hline \multirow{2}{*}{ व्यावसायिक क्षेत्र } & छात्राएँ (50) & & छात्र (50) & & \multirow{2}{*}{ ज मूल्य } & \multirow{2}{*}{ सार्थकता स्तर } \\
\cline { 2 - 5 } & $\mathbf{M}$ & S.D. & M & S.D. & & \\
\hline प्रवर्तक (P) & 9 & 2.803 & 8.98 & 2.569 & 0.0372 & सार्थक नहीं \\
\hline
\end{tabular}

सार्थकता-सारणी संख्या 8 में माध्यमिक स्तर के छात्र एवं छात्राओं की प्रवर्तक क्षेत्र की व्यावसायिक रुचियों की तुलना क्रान्तिक अनुपात (टी-मूल्य) के रूप में की गई है। प्राप्त टी-मान 0.0372 है, जो सार्थकता के 0.05 पर सार्थक नहीं है। अतः कहा
जा सकता है कि माध्यमिक स्तर के छात्र एवं छात्राओं की प्रवर्तक क्षेत्र की व्यवसायिक रुचियों में कोई सार्थक अन्तर नहीं है। अतः शून्य परिकल्पना को स्वीकार किया जाता है।

तालिका संख्या-9: माध्यमिक स्तर के छात्र एवं छात्राओं की सामाजिक (S) क्षेत्र की व्यावसायिक रुचियों की तुलना करना

\begin{tabular}{|c|c|c|c|c|c|c|}
\hline \multirow{2}{*}{ व्यावसायिक क्षेत्र } & छात्राएँ (50) & & छात्र (50) & & \multirow{2}{*}{ ज मूल्य } & \multirow{2}{*}{ सार्थकता स्तर } \\
\cline { 2 - 5 } & $\mathbf{M}$ & S.D. & M & S.D. & & \\
\hline सामाजिक (S) & 9.56 & 3.561 & 9.18 & 2.881 & 0.587 & सार्थक नहीं \\
\hline
\end{tabular}

सार्थकता-सारणी संख्या 9 में माध्यमिक स्तर के छात्र एवं छात्राओं की सामाजिक क्षेत्र की व्यावसायिक रुचियों की तुलना क्रान्तिक अनुपात (टी-मूल्य) के रूप में की गई है। प्राप्त टी-मान 0.587 है, जो सार्थकता के 0.05 पर सार्थक नहीं है। अतः कहा
जा सकता है कि माध्यमिक स्तर के छात्र एवं छात्राओं की सामाजिक क्षेत्र की व्यवसायिक रुचियों में कोई सार्थक अन्तर नहीं है। अतः शून्य परिकल्पना को स्वीकार किया जाता है।

तालिका संख्या-10: माध्यमिक स्तर के छात्र एवं छात्राओं की गृह सम्बन्धी $(\mathrm{H})$ क्षेत्र की व्यावसायिक रुचियों की तुलना करना

\begin{tabular}{|c|c|c|c|c|c|c|}
\hline \multirow{2}{*}{ व्यावसायिक क्षेत्र } & छात्राएँ (50) & & छात्र (50) & & \multirow{2}{*}{ ज मूल्य } & \multirow{2}{*}{ सार्थकता स्तर } \\
\cline { 2 - 5 } & $\mathbf{M}$ & S.D. & $\mathbf{M}$ & S.D. & & \\
\hline गृह सम्बन्धी (H) & 9.08 & 4.272 & 9 & 2.898 & 0.109 & सार्थक नहीं \\
\hline
\end{tabular}




\section{सार्थकता-}

सारणी संख्या 10 में माध्यमिक स्तर के छात्र एवं छात्राओं की गृह सम्बन्धी क्षेत्र की व्यावसायिक रुचियों की तुलना क्रान्तिक अनुपात (टी-मूल्य) के रूप में की गई है। प्राप्त टी-मान 0.109 है, जो सार्थकता के 0.05 पर सार्थक नहीं है। अतः कहा जा सकता है कि माध्यमिक स्तर के छात्र एवं छात्राओं की गृह सम्बन्धी क्षेत्र की व्यवसायिक रुचियों में कोई सार्थक अन्तर नहीं है। अतः शून्य परिकल्पना को स्वीकार किया जाता है।

\section{निष्कर्ष}

आंकड़ों के विश्लेषण के पश्चात् यह निष्कर्ष प्राप्त हुआ कि लिंगीय आधार पर माध्यमिक स्तर के छात्र एवं छात्राओं की व्यावसायिक रुचियों के अधिकांश क्षेत्रों में कोई सार्थक अन्तर नहीं है। रचनात्मक क्षेत्र में सार्थक अन्तर प्राप्त हुआ। जिसका कारण छात्र एवं छात्राओं की रुचि रचनात्मक कार्यों में भिन्न होती है। सामान्यतः बालिकाओं की रुचि रचनात्मक कार्यों में बालकों की अपेक्षा अधिक पाई जाती है।

अतः कह सकते हैं कि यदि छात्रों को किसी विशेष व्यवसाय के लिये उनकी रुचि के आधार पर उचित व्यावसायिक मार्गदर्शन प्रदान किया जाता है तो वे अपनी ऊर्जा की सही दिशा में उपयोग कर सकते हैं और इससे उनकी दक्षता में भी वृद्धि होगी।

\section{सन्दर्भ ग्रन्थ सूची}

1. Shah Rajul R. Tryout of Vocational Inventory on class9 to 12 students of Ahamedabad District. (Ahmedabad; Gujarat University, M.Ed Dissertation) 1999.

2. Musahid M. A comparative study of vocational interest of Muslim male and female students at secondary level in relation to achievment motivation. (Dissertation of M.Ed. Dept of Edu, AMU Aligarh.) 2002.

3. Howard Bitney \& Romand. Making Vocational Choice, A Theory of Carlars, New Jersey Prentic Hall 1973.

4. Asija Anurag. A Study of Vocational Interest of the adolescents in relation to their intelligence and Socioeconomic status (Scholarly Research Journal for Interdisciplinary studies 2016;4(36):10074. 